\title{
On the nature of nighttime ionisation enhancements observed with the Athens Digisonde
}

\author{
I. Tsagouri ${ }^{1}$ and A. Belehaki ${ }^{1}$ \\ ${ }^{1}$ Institute for Space Applications and Remote Sensing, National Observatory of Athens, Metaxa and Vas. Pavlou, P. Penteli \\ 15236, Greece
}

Received: 2 July 2001 - Revised: 19 March 2002 - Accepted: 22 March 2002

\begin{abstract}
True height electron density profiles observed with the Athens Digisonde were analyzed together with geomagnetic data indices for six magnetic storms in September and October 2000 in an effort to define the ionospheric structure during events of nighttime ionisation enhancements and to discuss the physical processes that may cause them. An upwelling of the F2-layer, limited to the dark hemisphere, was evident in all storm events as the ionospheric response to enhanced geomagnetic activity, but nighttime positive effects and nighttime height enhancements are attributed to two distinct mechanisms, according to our findings. Height enhancements are wave-like disturbances and the time delay of their occurrence at middle latitudes depends on the increase rate of the $A E$ index, and consequently, on the rate that the solar wind input energy dissipates in the auroral ionosphere. Thus, they most probably originated in the auroral oval region and propagated toward the equator-like TID disturbances, with a periodicity that depends on the ionisation density. On the other hand, $f o \mathrm{~F} 2$ increases do not share the same wavy appearance, which could mean that they are not connected to TIDs and are not of auroral oval origin. The increased nighttime density can only be speculated to be due to increased downward fluxes from the plasmasphere.
\end{abstract}

Key words. Ionosphere (ionosphere-magnetosphere interactions; ionospheric disturbances; mid-latitude ionosphere)

\section{Introduction}

The ionosphere-thermosphere system response to geomagnetic storms is initiated at high latitudes, where energetic particle precipitation, convection electric fields and associated Joule heating are taking place. The Prölss (1993) phenomenological model represents one of the most popular descriptions of the ionospheric storm-induced effects, which was further extended by Fuller-Rowell et al. (1994; 1996), although in this model only daytime positive storm effects are

Correspondence to: I. Tsagouri (tsagouri@ space.noa.gr) predicted. According to this description negative ionospheric storm effects are attributed to neutral composition changes, while daytime positive effects are attributed to travelling atmospheric disturbances (TADs). A TAD is a thermospheric phenomenon, which accompanies atmospheric gravity waves (AGWs). During a substorm associated energy injection at auroral latitudes, a whole spectrum of gravity waves is generated. At some distance from the source region these waves will be superimposed to form an impulse-like perturbation, the TAD, which moves with high velocity from auroral to equatorial latitudes (Bauske and Prölss, 1997). The AGWs and the TADs have been studied in great detail, usually by observing the associated so-called travelling ionospheric disturbances (TIDs), which describe the effect of the TADs on the ionosphere (Balthazor and Moffett, 1999). A particularly useful ionospheric tracer of TIDs was found to be the peak height of the F2-layer, $h m$ F2. In Prölss's scenario, positive storm effects are caused by an uplifting of the F2-layer at any mid-latitude station located in the sunlit hemisphere. The storm-induced effects scenario in the night-side hemisphere is different. Here, the lack of ionisation production will not allow for the formation of large positive effects, although TAD-associated changes in the layer height will be observable at any local time.

Within the last few years, it was well confirmed that positive storm effects are also observed in the night-side hemisphere (Oliver and Hagan, 1991; Burnside et al., 1991; Szuszczewicz et al., 1998; Tsagouri et al., 2000; Belehaki and Tsagouri, 2002). They are also predicted by numerical simulations (Mansilla and Manzano, 1998) and many responsible mechanisms have been occasionally proposed. For example, Oliver and Hagan (1991), in a study of storm-induced gravity waves, invoked the assumption of downward plasmaspheric fluxes as a source of enhanced nighttime densities. This mechanism is an open issue even in normal conditions (Szuszczewicz et al., 1998). It is not ascribed to any storm mechanism, although there is observational and theoretical evidence for the existence of storm time gravity-waveinduced perturbations in atmospheric densities (Trinks and 
Mayr, 1976; Mayr and Volland, 1976; Potter et al., 1976). These perturbations can cause ionospheric perturbations in combination with the ionisation existence in the night side. Burnside et al. (1991) attributed unusually high nighttime densities to converging plasma flow in the $\mathrm{F}$ region due to a surprisingly large vertical shear in the meridional wind velocity, rather than to a decrease in the molecular gas density and the subsequent reduction in the ion recombination rate (that may occur in the case of thermospheric downwelling), while Mansilla and Manzano (1998) considered an uplifting of plasma to higher altitudes as the main cause of nighttime positive effects.

According to Fuller-Rowell et al. (1994), initial positive phases are wind driven effects observed in the daytime during the main phase of the storm, consistent with the consensus picture. They also maintain that if a positive phase is driven by winds before dusk, it will rotate into the nightside and nighttime positive effects of this type have been observed (Szuszczewicz et al., 1998; Tsagouri et al., 2000). However, the understanding of positive phase observations is not always so simple, such as in cases of nighttime initiated positive effects. Thermospheric downdwelling with an associated decrease in mean-molecular-mass and an attendant reduction in dissociate recombination is a mechanism invoked by Fuller-Rowell et al. (1994) to be present in the recovery phase. This could also be the case in the expansion phase. Downdwelling could be a candidate mechanism for positive phase storms commencing at night (Szuszczewicz et al., 1998). In a recent work, Belehaki and Tsagouri (2002) demonstrated that the existence of a new source of ionisation is necessary to explain nighttime positive effects and, therefore, the increased nighttime density can only be speculated to be due to increased downward fluxes from the plasmasphere (Rishbeth, 1987; Richards, 1994). In fact, the plasmaspheric flux term can also modify the value of $h m \mathrm{~F} 2$ and contribute to the height increase (Szuszczewicz et al., 1998).

Finally, Belehaki and Tsagouri (2002) attributed the latitudinal effect in observation of nighttime ionisation enhancements at middle latitudes to the solar wind-magnetospheric coupling conditions, which may cause a restriction in the neutral composition disturbance zone to higher latitudes. In such cases, the observation of the effects of plasmaspheric fluxes at middle latitudes is more probable.

From the above short review in the recent literature, it is obvious that the question of the triggering mechanism of nighttime ionisation enhancements observed systematically from middle latitude stations is not answered yet. In this contribution, we will make an effort to approach this problem by analyzing data from ionospheric soundings taken with the Athens Digisonde Portable Sounder (Reinisch, 1996). The systematic study of the calculated electron density profiles during several storm intervals aims to determine the ionospheric structure during events of nighttime ionisation enhancements and to investigate the possible mechanisms that produce such type of disturbances.

\section{Events overall perspective}

This work is based on the study of three storm periods that occurred in September and October 2000. Six distinct magnetic storms were determined. These events were studied in detail in the light of the global solar wind-magnetosphereionosphere interaction in a previous work (Belehaki and Tsagouri, 2002), where the conditions under which nighttime positive effects occur in the middle latitude ionosphere were determined and a possible mechanism that drives these phenomena was also discussed. Regarding the ionospheric mechanism responsible for the height variations, it was demonstrated that during either positive or negative nighttime effects, an upwelling of the F2-layer occurred in association with disturbed periods. To further investigate the impact of the geomagnetic activity on the ionospheric structure, and thus, the origin of positive storm phases, the ionospheric response over Athens in height structure and in electron density is studied in more detailed during selected magnetic storms, using true height profile data from the Athens $\left(103.5^{\circ} \mathrm{E}, 36.23^{\circ} \mathrm{N}\right.$ geomagnetic) digisonde.

The Athens Digisonde Portable Sounder autoscales the ionograms and provides radio channel information in real time. Data and ionograms are available in real time on the World Wide Web via our home page (http://www.iono.noa.gr). Polarisation switching and multibeam forming are the important prerequisites for successful autoscaling under disturbed and undisturbed conditions. Autoscaling algorithms find the leading edge of the $\mathrm{O}$ echo traces, i.e. $h^{\prime}(f)$, and determine the standard ionosphere characteristics. ARTIST software provides reliable vertical electron density profiles, using the Chebyshev polynomial fitting technique (Reinisch and Huang, 1983; Huang and Reinisch, 1996). Regarding the topside vertical electron density profile, the new technique of Huang and Reinisch (2001) is applied. This method uses information from ground-based ionosonde measurements. The profile above the peak is approximated by an $\alpha$-Champan function, with a scale height that is derived from the profile shape at the F2 peak.

To have an indicator of the auroral oval activity, the values of the four $A E$ magnetospheric indices with $1 \mathrm{~min}$ resolution are used, provided by WDC-C2 Kyoto (http://swdedb. kugi.kyoto-u.ac.jp/wdc/). It has to be noted that these are the preliminary values of the $A E$ indices, which explain the existence of some spikes. However, these artificially large values are discernible and thus, they do not affect the physical information extracted by the indices. The $A E$ index and also the joint $A U$ and $A L$ indices were introduced by Davis and Sugiura (1966) as a measure of the global auroral electrojet activity. The $A U$ and $A L$ indices are monitoring the eastward and westward electrojets, respectively, while the $A E$ index, which is equal to the difference $A U$ $A L$, corresponds to the separation between $A U$ and $A L$ envelopes. It depends solely upon the maximum eastward and westward electrojet currents and is independent of zonal currents, if any, existing in the high-latitude ionosphere. The $A O$ index $[A O=(A U+A L) / 2]$ is "an approximate mea- 


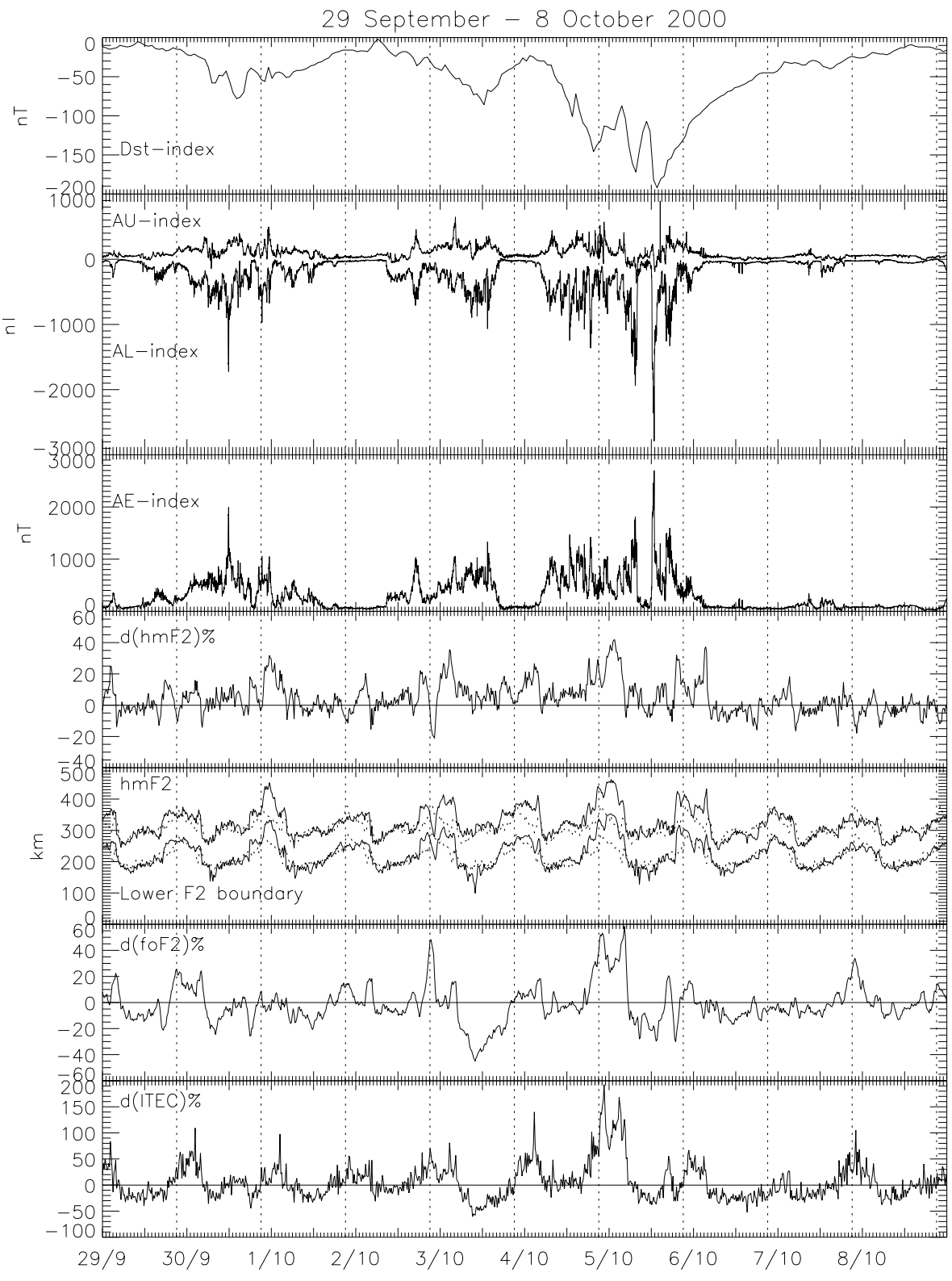

Fig. 1. The overview plot that describes the ionospheric conditions over Athens in response to geomagnetically disturbed conditions recorded from 29 September to 8 October 2000 are presented. The development of the $D_{s t}$ index is presented in the first panel, in hourly resolution. In the following two panels, the 1-min values of the $A U$, $A L$ and $A E$ indices are presented. The vertical dotted lines indicate the local midnight. The variations in the peak height of the F2-layer are presented in the fourth panel of Fig. 1. In terms of the $\mathrm{d}(h m \mathrm{~F} 2) \%$ deviations from the quiet values, the peak height of the F2layer, together with the lower F2-layer boundary $(h m \mathrm{~F} 2-B 0)$, are given in the following panel, and finally, the relative $\mathrm{d}(f \circ \mathrm{F} 2) \%$ deviations with respect to quiet values for this time interval followed by the d(ITEC)\% variations are plotted in the two bottom panels. The solid lines represent the observed parameters, while the dotted lines represent their diurnal quiet time pattern. sure of the equivalent zonal current" (Mayaud, 1980). According to Akasofu (1981), the $A E$ index is a very good indicator of the physical processes that occurred in the auroral ionosphere following an episode of enhanced solar wind energy input. The magnetosphere dissipates the input solar wind power partly to the auroral ionosphere as kinetic power of the auroral particles $\left(U_{A}=A E \cdot 10^{15} \mathrm{erg} / \mathrm{s}\right)$ is lost in the ionosphere due to collisions and since Joule heating $\left(U_{j}=2 \cdot 10^{15} A E \mathrm{erg} / \mathrm{s}\right)$ is associated with electric current flow in the resistive ionosphere. Hence, the use of auroral electrojet indices may lead to useful information regarding the amount of energy accumulated in the auroral ionosphere and consequently, transformed to kinetic and thermal energy during the course of a substorm episode in the auroral ionosphere.
To have a measure of the ring current injection rate as the magnetospheric response to the solar wind, the hourly values of the preliminary $D_{s t}$ index provided by WDC-C2 Kyoto are used (http://swdcdb.kugi.kyoto-u.ac.jp/wdc/).

29 September -8 October 2000: The overview plot that describes the ionospheric conditions over Athens in response to geomagnetically disturbed conditions recorded during this period is given in Fig. 1. The development of the $D_{s t}$ index is presented in the first panel, in hourly resolution. In the following two panels, the one-minute values of the $A U, A L$ and $A E$ indices are presented. The vertical dotted lines indicate the local midnight.

This period covers a time interval of 10 days and consists of two distinct geomagnetic storms. The first geomagnetic storm is gradually driven and results from a low level so- 
lar wind-magnetospheric coupling (Belehaki and Tsagouri, 2002). It is characterized by moderate intensity and fully recovers on 1 October at 21:00 UT, as indicated by both $A E$ and $D_{s t}$ indices. The second storm is more intense and its development consists of two distinct steps. The start of the $D_{s t}$ decrease ( $\sim$ 07:00 UT on 2 October) is followed by an activation of the $A E$ magnetospheric indices almost immediately. First, a sharp decrease in $A L$ indicates that the triggering of this substorm results from the unloading of energy from the tail. During the progress of the event, the two mechanisms, driven and loading-unloading, seem to operate simultaneously, as indicated by the more or less symmetric development of the $A L$ and $A U$ indices. This storm seems to recover at 02:00 UT on 4 October. Meanwhile, the $D_{s t}$ reached a minimum of $-86 \mathrm{nT}$ and the $A E$ index reached values of $1000 \mathrm{nT}$, indicating moderate geomagnetic activity and a high level auroral oval activity. Right afterwards, the $D_{s t}$ index starts to decrease again with a high rate of change, marking the initial phase of the second step of this storm, which coincides with a reactivation of the magnetospheric activity. This time the $D_{s t}$ index reached a minimum of $-192 \mathrm{nT}$ at 14:00 UT on 5 October, while the $A E$ index exceeded $1000 \mathrm{nT}$, reaching values of $2000 \mathrm{nT}$. This storm can be classified as a Type B storm (Kamide et al., 1998) as the ring current presents a two-step development. This is initially the result of large-scale convection in the magnetosphere, and eventually, the substorm associated injection of ionospheric oxygen ions into the inner magnetosphere.

The ionospheric observations during this period from the Athens Digisonde, which performs routine vertical soundings every $15 \mathrm{~min}$, are presented in the last four panels of Fig. 1. Although the ionograms were automatically scaled, all the ionograms data were further edited to ensure data integrity and minimize uncertainties, especially during periods of high disturbances. Three F2-region characteristics, the critical frequency $f o \mathrm{~F} 2$, the peak height of the F2layer, $h m \mathrm{~F} 2$, and the $\mathrm{F} 2$ thickness parameter, $B 0$ (Reinisch and Huang, 1998), in addition to the total electron content (ITEC) estimates, were used to extract these plots. All parameters were compared to their diurnal quiet time behaviour, formed by the average of the quiet days 20 October $\left(-2 \mathrm{nT}<D_{s t}<7 \mathrm{nT}\right.$ and $\left.K_{p}<1\right)$ and 21 October $\left(0 \mathrm{nT}<D_{s t}<18 \mathrm{nT}\right.$ and $\left.K_{p}<2-\right)$, when no substorm activity was detected by the $A E$ indices. Also, during the day before, 19 October 2000, only weak isolate substorm activity was recorded by the $A E$ index at auroral latitudes, when $-13 \mathrm{nT}<D_{s t}<3 \mathrm{nT}$ and $K_{p}<3$. More precisely, the variations in the $h m \mathrm{~F} 2$ are presented in the fourth panel of Fig. 1 in terms of the $\mathrm{d}(h m \mathrm{~F} 2) \%$ deviations from the quiet values, and the $h m \mathrm{~F} 2$, together with the lower F2-layer boundary $(h m \mathrm{~F} 2-B 0)$, is given in the following panel. Finally, the relative $\mathrm{d}\left(f_{o} \mathrm{~F} 2\right) \%$ deviations with respect to the quiet values for this time interval, followed by the d(ITEC)\% variations, are plotted in the two bottom panels. The solid lines represent the observed parameters, while the dotted lines represent their diurnal quiet time pattern. In reviewing the data in Fig. 1, the following points are noted:
1. Systematic nighttime positive effects appear in $\mathrm{d}(f \circ \mathrm{F} 2) \%$ variations around local midnight. The positive deviations in plasma frequency ranged from 5\% (negligible) to $60 \%$ (156\% density enhancement), with the more intense effects occurring in the more magnetospherically active periods. The maximum nighttime ionisation enhancement occurred at night between 4 and 5 October (156\%). It is noticeable that immediately afterwards, a well-defined SSC occurring at 03:26 UT caused a new activation of the storm main phase. This sudden release of a large amount of energy to the magnetosphere-ionosphere system had, as a consequence, the lack of positive effects during the two following nights (5-6 and 6-7 October) (Belehaki and Tsagouri, 2002). Noticeable enhancements were also observed at night from 29 to 30 September (50\% density enhancement), from 2 to 3 October $(120 \%$ density enhancement), and from 7 to 8 October (40\% density enhancement), during ring current and auroral injection phases.

2. The d(ITEC)\% variations are well correlated, with the $\mathrm{d}(f \circ \mathrm{F} 2) \%$ variations showing the same development pattern during the whole sequence of the events and indicating net ionisation enhancements during nighttime positive effects.

3. The nighttime ionosphere structure is also an interesting feature of this event. Most of the nighttime intervals are characterized by an F2-layer uplifting, observed from 19:00 to 06:00 LT, while during daytime hours the ionosphere recovers to normal heights. Significant deviations of the observed $h m \mathrm{~F} 2$ values with respect to the quiet values (from $20 \%$ to $40 \%$ ) occurred at night between 29-30 September, 2-3, 4-5 and 56 October, accompanied by nighttime positive effects. Also, noticeable deviations in $h m \mathrm{~F} 2$ occurred at night between 30 September and 1 October, when the ionisation density over Athens remained primarily at its quiet values. Nevertheless, during that night, significant auroral activity was detected by the $A E$ index, although $D_{s t}$ remained at fairly weak levels of activity. This fact, together with the observation that the uplifting of the F2-layer is much more evident as the solar windmagnetosphere coupling reaches higher levels, gives evidence that the variation of the peak height of the F2layer is probably dependent on the energy deposited by the solar wind in the auroral ionosphere, as described by the $A E$ index. Indeed, during the night hours, between 29-30 September, a weak height increase was observed, probably caused by the very weak auroral activity indicated by the $A E$ index, although significant ionisation enhancement (more than $40 \%$ density enhancement) was observed over Athens during that night.

4. No consistent relation between peak density and height was found; thus, the occurrence of nighttime positive effects seems to be independent of the variations in height. 
12-16 October 2000: The overview plot for this event is presented in Fig. 2 in the same format as in Fig. 1. At the beginning of this interval, the magnetosphere-ionosphere system was in a moderately disturbed state. The start of this storm can be determined as the time of occurrence of a SSC detected at 22:28 UT on 12 October, which results in a rapid ring current development and a rapid increase in all $A E$ indices as well. The initial and main storm phases lasted for about $6 \mathrm{~h}$, as seen by the $D_{s t}$ development. The $D_{s t}$ reached a minimum of $-63 \mathrm{nT}$. During this six-hour interval, the $A E$ index reached extremely large values $(\sim 1500 \mathrm{nT})$, indicating very strong Joule heating in the auroral oval. The storm recovery phase lasted $9 \mathrm{~h}$. Six hours later, a second gradually driven storm was detected. This storm had no initial phase. Its main phase lasted more than $24 \mathrm{~h}$, due to slowly increasing southward $B_{z}$-IMF (Belehaki and Tsagouri, 2002). Probably, the large-scale magnetospheric convection caused the slow development of the ring current, as indicated by the slowly decreasing $D_{s t}$ index. Indeed, the start of this storm was marked by the asymmetric enhancement of $A U$ and $A L$ indices recorded between 17:00 UT and 21:00 UT on 13 October. The $A U$ was severely disturbed and the $A L$ index decreased very slowly, indicating the energisation of the directly driven mechanism that directly dissipates the solar wind input energy in the auroral ionosphere. The last four panels present again the relative deviations of $h m \mathrm{~F} 2$ from the quiet day values, $h m \mathrm{~F} 2, h m \mathrm{~F} 2-B 0, \mathrm{~d}(f o \mathrm{~F} 2) \%$ and $\mathrm{d}(\mathrm{ITEC}) \%$. The diurnal quiet time behaviour at Athens, overplotted in the sixth panel, is again formed by the average of the quiet days, 20 and 21 October. The main observations may be summarized as follows:

1. Negative effects are observed at night from 12 to 13 October. This is the ionospheric response to the first storm event that was caused by an SSC. This ionisation depletion event was accompanied by a very large increase in height (almost 60\%), initiated one hour after the sharp and large increase in the $A E$ index (00:40 LT), when Athens was still on the night side.

2. During the second night of this time interval (13 to 14 October) that corresponds to the initial and main phases of the second storm, positive nighttime effects are evident over Athens. The foF 2 deviations with respect to the quiet values reached $20 \%$. Noticeable height enhancements were observed during that night. The time variation of $\mathrm{d}(h m \mathrm{~F} 2)$ has the same behaviour as the $A E$ index, shifted slightly in time: it is obvious that the very large increase in height at 03:00 LT is related to the $A E$ increase detected at 00:00 LT.

3. The same pattern of ionisation enhancement with stronger intensity (this time a maximum of $70 \%$ was recorded) was observed during the next night (14 to 15 October) and also during the last night of this storm event interval (15 to 16 October), although its intensity is obviously attenuated. Although the magnetic storm was in its recovery phase during the last two nights, significant auroral electrojet injections are still recorded by all $A E$ indices. Thus, it is not surprising that despite the fact that the geomagnetic storm is in its recovery phase, the auroral activations produced significant height increases at night, which exceeded $20 \%$.

4. The d(ITEC)\% variations are well correlated to the $\mathrm{d}(f \circ \mathrm{F} 2) \%$ variations in both negative and positive phases. Once again, nighttime positive effects are associated with total electron content enhancements.

5. Again, no consistent relation between the peak density and height was found.

16-21 September 2000: This storm time interval is presented in Fig. 3, which follows the format of Figs. 1 and 2. This event was the result of an interplanetary coronal mass ejection (ICME) detected in the analysis of ACE solar wind data by Belehaki and Tsagouri (2002). The $D_{s t}$ index was already depressed and the $A E$ indices were activated prior to the arrival of a fast forward shock approximately at 19:00 UT on 17 September. Immediately after the shock arrival, the $D_{s t}$ index decreased very rapidly, reaching its minimum value of $-172 \mathrm{nT}$ at 23:00 UT on 17 September. The $A E$ index reached values of $2000 \mathrm{nT}$, although there are some spikes exceeding the $2000 \mathrm{nT}$, but these might be attributed to the fact that these are preliminary values of the $A E$ index. The very sharp decrease in the $A L$ index indicates a very sudden energisation of the westward auroral electrojet fed by the cross tail current disruption. While the system recovered, at 14:44 UT on 18 September a new SSC caused a deceleration in $D_{s t}$ recovery and an intensification of the auroral electrojets, apparent in $A E$. Finally, at 06:00 UT on 19 September, new storm activity is produced. $D_{s t}$ reached the minimum value of $-80 \mathrm{nT}$ on 19 September, which recovered slowly until the end of the next day. During this last event, rather intense substorm activity is recorded, with the $A E$ index having values up to $1000 \mathrm{nT}$. The behaviour of the ionosphere at middle latitudes is presented in the last panels of the Fig. 3. The diurnal quiet time behaviour of each parameter is now formed by the corresponding observations during the quiet day 11 September $\left(9 \mathrm{nT}<D_{s t}<24 \mathrm{nT}\right.$ and $K_{p}<1$ ), when no substorm activity was detected by the $A E$ indices. Also, during the day before, 10 September 2000, no substorm activity was recorded by the $A E$ index at auroral latitudes, when $0 \mathrm{nT}<D_{s t}<20 \mathrm{nT}$ and $K_{p}<1$. In reviewing the data in Fig. 3, the following points are noted:

1. Nighttime ionospheric behaviour was characterized by ionisation depletion during the two successive storms discussed above. The $\mathrm{d}\left(f_{o} \mathrm{~F} 2\right) \%$ variations are well correlated with $\mathrm{d}(\mathrm{ITEC}) \%$ variations.

2. Noticeable uplifting of the F2-layer is observed during the first two nights of this interval (16 to 17 and 17 to 18 September), with the maximum increase in height observed the second night of the major storm occurrence and when the $D_{s t}$ and $A E$ indices recorded 


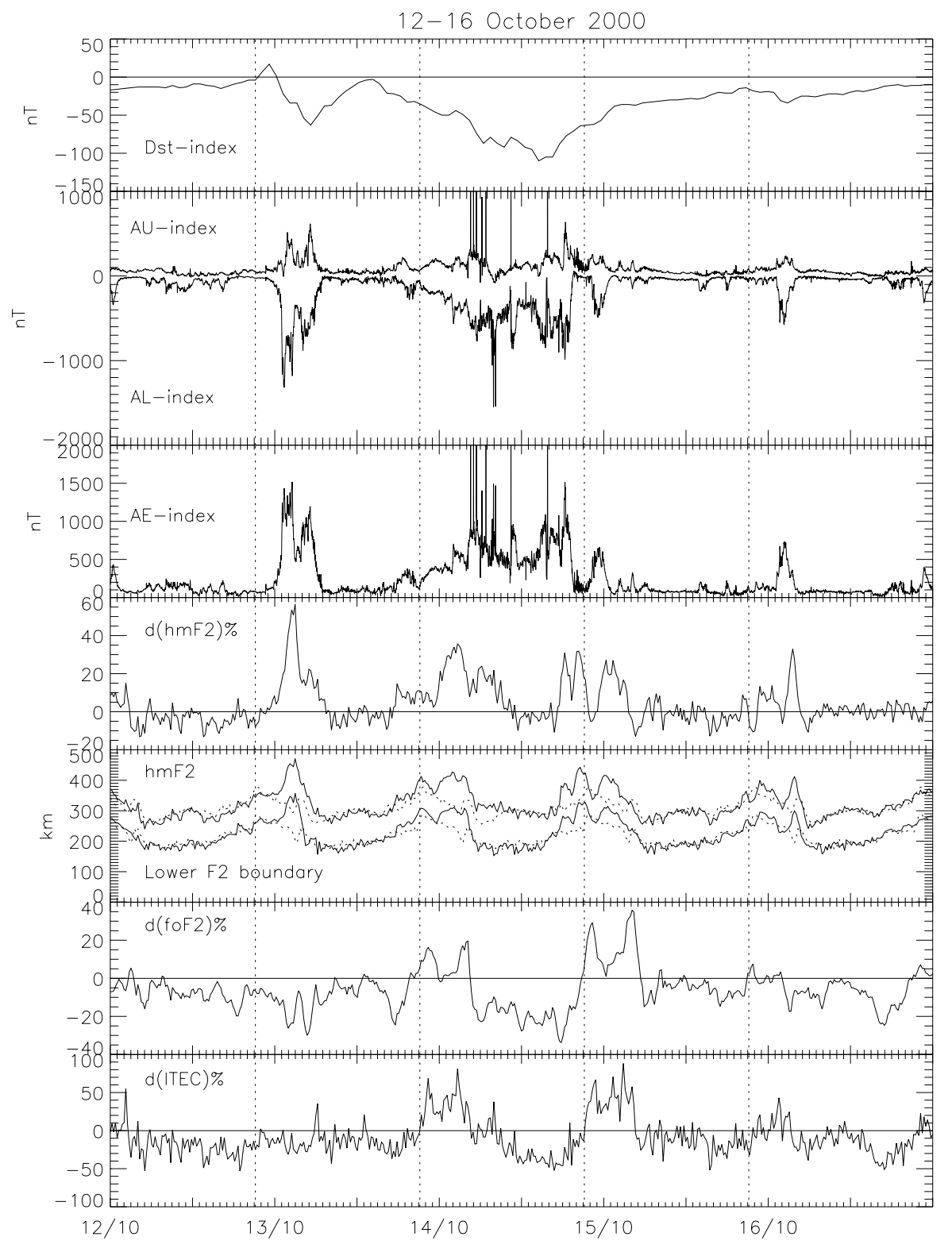

Fig. 2. Same as Fig. 1 for the interval 12-16 October 2000. their maximum for this time interval. No significant height increase was observed during the second storm event. Indeed, the auroral oval activity expressed by the $A E$ index was in low levels during this event, although some peaks in $h m \mathrm{~F} 2$ some hours after local midnight on 20 and 21 September coincide with enhancements of the auroral oval activity.

Summarizing the above observations we can note the following first results: an upwelling of the F2-layer, limited to the dark hemisphere, in response to enhanced geomagnetic activity, is evident in all of the storm events under study. These increases are common features of the ionospheric behaviour during events of either ionisation depletions or enhancements at night. They are apparent even in storm recovery phases, always limited to the dark side hemisphere, and the more intense effects occur during the more magnetospherically active periods. Hence, one could say that their occurrence and their characteristics (strength, LT initiation and duration) depend strongly on the auroral activity and the $A E$ index development, in particular. The following sections investigate the characteristics of the observed height enhancements to explore the nature of these mechanisms.

\section{Height enhancements characteristics}

The 3-D plots of the true height variation for various plasma frequencies during nighttime hours are presented below in an effort to study the nighttime ionospheric height structure during disturbed periods. In Fig. 4, the density structure during the night between 20 and 21 October 2000 is presented. 


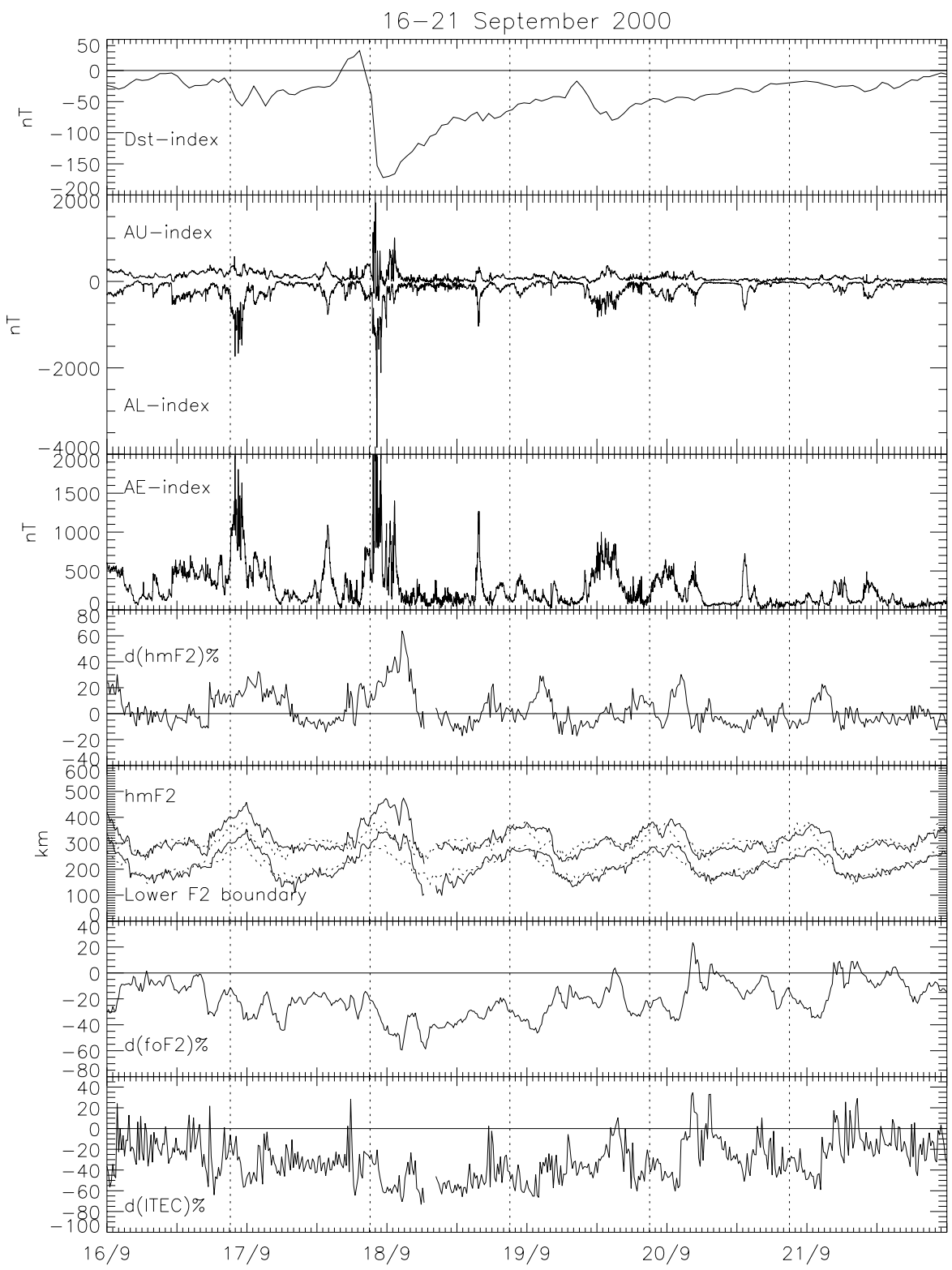

Fig. 3. Same as Fig. 1 for the interval 16-21 September 2000.
This is a very quiet interval and is taken as a reference. In Figs. 5 and 6 , the density structure for two nights (2-3 October and 13-14 October, respectively), during which ionisation enhancements are observed over Athens, are presented as characteristic examples. Finally, two nighttime intervals (17-18 September and 12-13 October) were selected as representative cases for ionisation depletion events and are presented in Figs. 7 and 8.

During the night from 20 to 21 October 2000 (Fig. 4), geomagnetically quiet conditions lead to a rather normal ionospheric height-density structure. No fluctuations are observed, except possibly for an abrupt rise around 23:00 LT and another one around sunrise, which are expected features of the nighttime ionospheric structure before sunrise (Rishbeth and Garriott, 1969; Oliver and Hagan, 1991).

Then we investigated the cases of nighttime positive ef- fects. Two characteristic examples are presented in Figs. 5 and 6. Intense fluctuations are evident in almost all of the nights under study. For all 5 cases of this group, some common features can be reported:

1. Height fluctuations are always initiated around local sunset and seem to terminate around local sunrise. During daytime hours, the fluctuations are totally absent.

2. The period of the fluctuations does not remain constant during an event, and is not the same at all plasma frequencies, making it difficult to specify a typical period. In general, smaller periodicities (of 1 or $2 \mathrm{~h}$ ) are observed before local midnight, while after local midnight the periodicity is increased (to about $4 \mathrm{~h}$ ) before the disturbance is totally attenuated. This observation may be connected to the fact that the F2-layer is denser, before 
20-21 October 2000

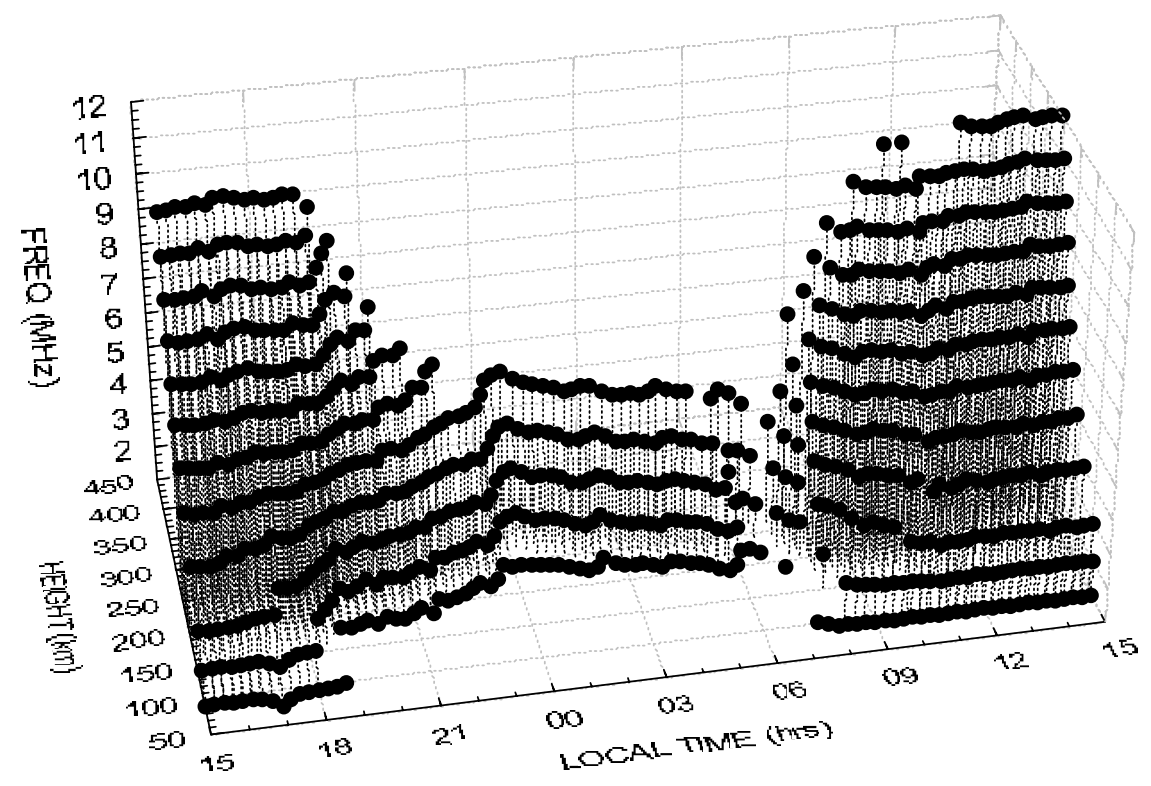

2-3 October 2000

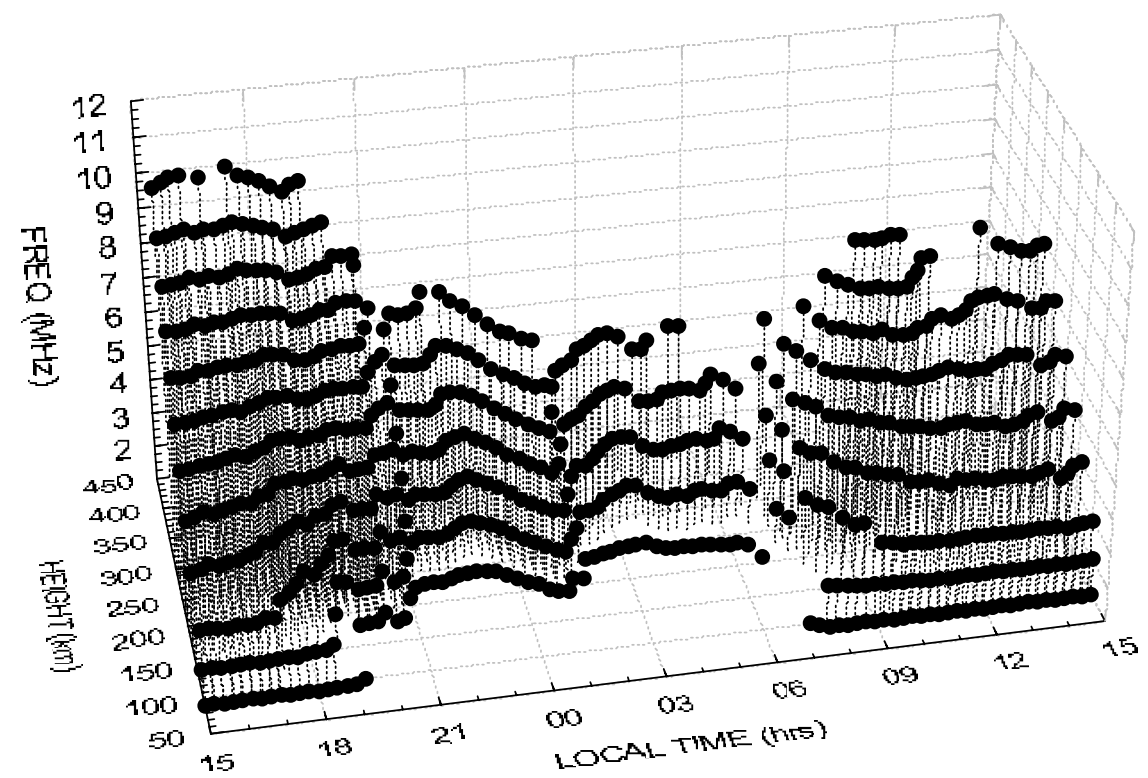

Fig. 4. The 3-D plot of the height variation for plasma frequencies $2-12 \mathrm{MHz}$ versus the local time for the night hours between 20 and 21 October 2000. This is an undisturbed night taken as the quiet reference.
Fig. 5. The 3-D plot of the height variation for plasma frequencies $2-12 \mathrm{MHz}$ versus the local time for the night hours between 2 and 3 October 2000. Ionisation enhancement was observed over Athens. local midnight. A tendency for increasingly smaller periodicities at increasingly higher frequencies has also been found.

3. The amplitude of the height fluctuation ranges from 50 to $100 \mathrm{~km}$, depending on altitude and/or frequency.

Nighttime periods characterized by negative storm effects are discussed next. From the four cases reported in this investigation, only two indicative examples are presented in Figs. 7 and 8, for the nighttime intervals of 17-18 September and 12-13 October, respectively. Summarizing our results, we can report:

1. Wave-like perturbations in height can be clearly recog- nized during all nights of ionospheric depletion. Once again, the disturbance started around local sunset and declines around local sunrise. During daytime hours, no propagating waves were observed.

2. The periodicity behaviour is similar to the pattern derived before, although the values are somewhat larger, typically $3 \mathrm{~h}$ before local midnight, and 4.5-5 afterward. This difference may be attributed to the fact that the F2layer is less dense during ionisation depletion events.

In summary, the observed height variations have wave-like characteristics. Their periodicity ranges from $1 \mathrm{~h}$ to $5.5 \mathrm{~h}$, tending toward smaller periodicities during ionisation en- 
13 - 14 October 2000

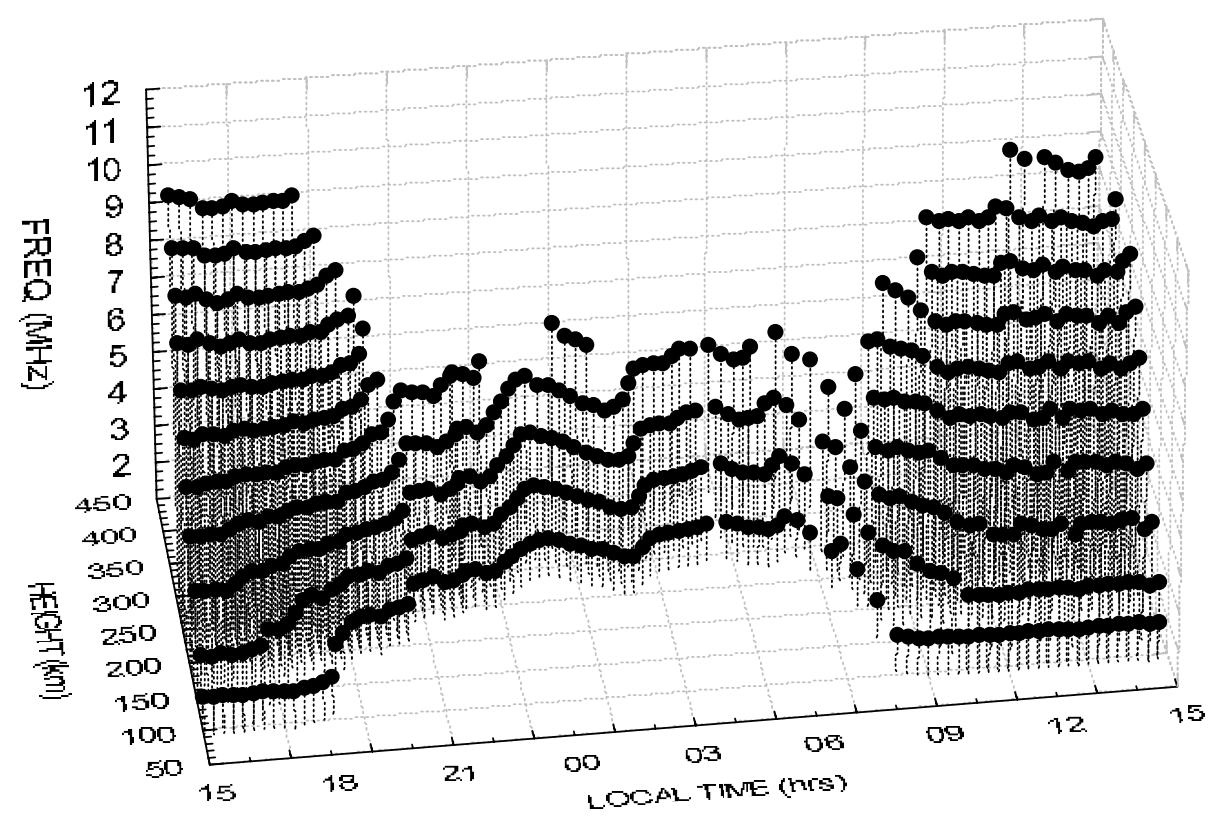

17-18 September 2000

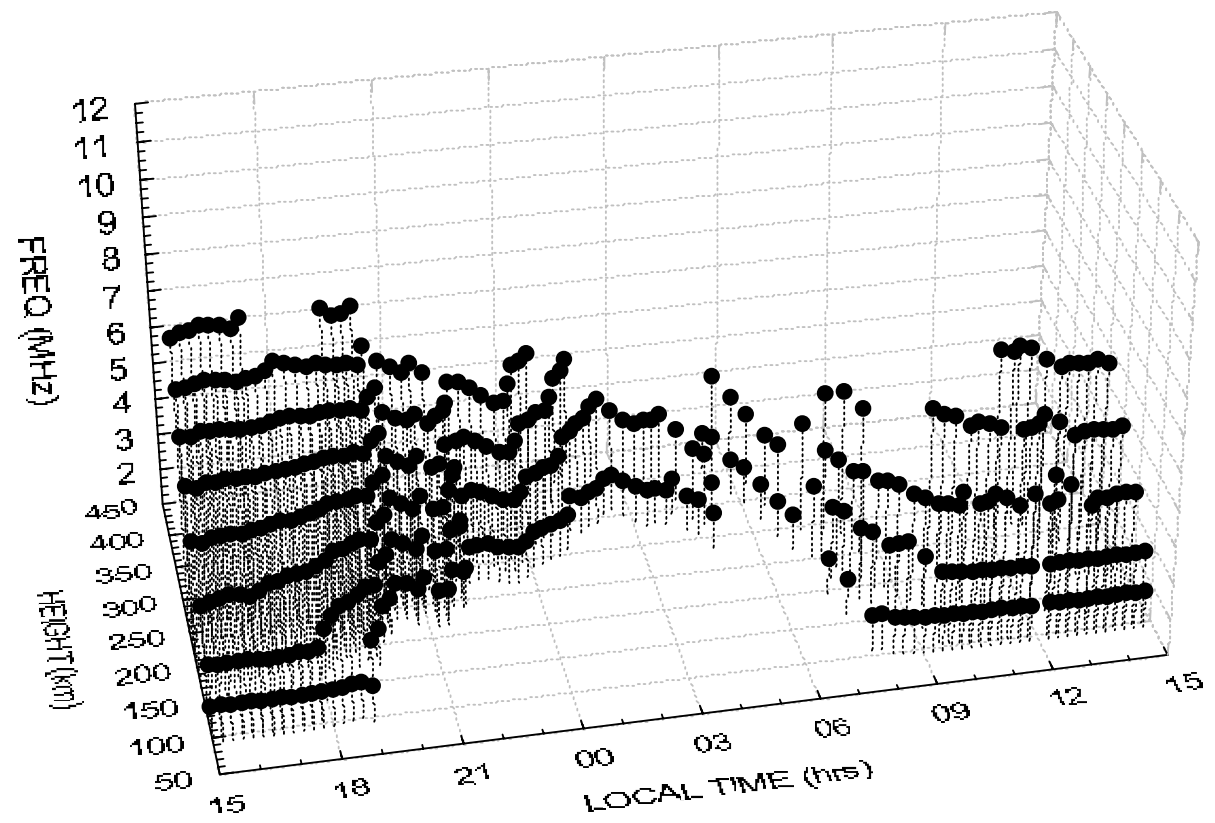

Fig. 6. The 3-D plot of the height variation for plasma frequencies $2-12 \mathrm{MHz}$ versus the local time for the night hours between 13 and 14 October 2000. Ionisation enhancement was observed over Athens.
Fig. 7. The 3-D plot of the height variation for plasma frequencies $2-12 \mathrm{MHz}$ versus the local time for the night hours between 17 and 18 September 2000. Ionisation depletion was observed over Athens. hancements and before local midnight, when the ionisation density is greater. This dependence on ionisation density may be a possible explanation for the wave-like enhancements observation to be more evident during nighttime positive effects. Moreover, a dependency of the periodicity on the frequency and/or altitude may be explained in terms of the atmospheric density decrease with altitude (Richmond and Lu, 2000). During daytime hours, the fluctuations have totally disappeared, but then other mechanisms, such as ion drag, dominate (Hajkowicz, 1990; Balthazor and Moffett, 1999).

\section{Auroral activity and height enhancements}

The observations described above imply a temporal correlation between the appearance of height enhancements and $A E$ index injections. Moreover, the characteristics of the nighttime ionospheric structure (i.e. wavy disturbances, periodicity and amplitude of observed variations) might be related to the quantitative characteristics of the $A E$ index injections. To further investigate this dependence, we compared the $A L$, $A U$ and $A E$ indices evolution with the $\mathrm{d}(h m \mathrm{~F} 2) \%$ deviations individually for each event of nighttime uplifting of the F2- 
12-13 October 2000

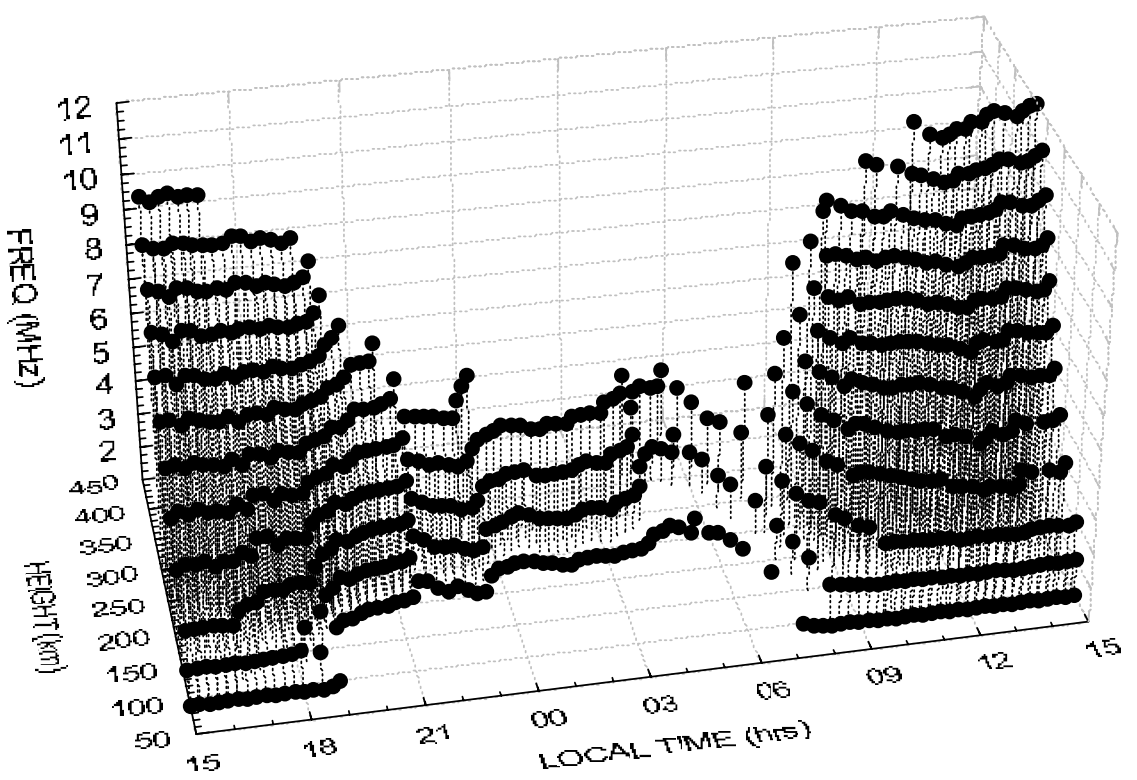

Fig. 8. The 3-D plot of the height variation for plasma frequencies $2-12 \mathrm{MHz}$ versus the local time for the night hours between 12 and 13 October 2000. Ionisation enhancement was observed over Athens. layer. Since height enhancements were observed between 18:00 and 06:00 in LT, we concentrated on this range of hours, using $A E$ indices and $h m \mathrm{~F} 2$ data with 15 -min resolution. The variations of the $A E$ indices, together with the $\mathrm{d}(h m \mathrm{~F} 2) \%$ deviations for the night intervals presented in the previous section, are shown in Fig. 9(a-d). The following assumptions were made in order to study the effect of auroral energy injection on ionospheric height variations: first, we consider as significant height deviations those exceeding the $10 \%$ level with respect to normal height values. Second, we regard as a reasonable threshold for the auroral activity affecting the ionosphere at geomagnetic latitudes over Athens $\left(36.23^{\circ} \mathrm{N}\right)$ the value of $300 \mathrm{nT}$ for $A E$. Auroral activations that cause $A E$ disturbances with less than $300 \mathrm{nT}$ produce height variations of less than $10 \%$.

The $A E$ indices, together with the $\mathrm{d}(h m \mathrm{~F} 2) \%$ deviations for the night of 2-3 October, are presented in Fig. 9a. The energy injection, indicated by the $A E$ index's rapid increase starting at 18:30 LT, seems to result in the first height disturbance (of about 20\%) $2 \mathrm{~h}$ later. A very smooth deviation in both auroral electrojet indices, implying direct deposition of the solar wind energy to the auroral ionosphere that started at 01:45 LT, led to a gradual increase in the $A E$ index. The height enhancement followed with a time delay of $35 \mathrm{~min}$.

The night of 12-13 October (Fig. 9b) is the most interesting one, since it is the most representative of our study corresponding to ideal conditions. The $A E$ index was really low from 19:00 to about 03:00 LT and no significant $h m \mathrm{~F} 2$ deviations were observed at Athens. At 03:25 LT, a single rapid increase in the $A E$ index was recorded (the $A E$ index reached its maximum value $1300 \mathrm{nT}$ in $45 \mathrm{~min}$ ), indicating that the unloading mechanism in energy dissipation is the dominant one and this time, the associated height rise started almost simultaneously (with a 5-min delay). The maximum $h m \mathrm{~F} 2$ deviation was about $55 \%$ for this night. During next night (Fig. 9c), a gradual increase in the $A E$ index led to a prolonged increase in $h m \mathrm{~F} 2$ with a 90-min delay. The maximum deviation in $h m \mathrm{~F} 2$ was $35 \%$. Finally, the $A E$ indices, together with the $\mathrm{d}(h m \mathrm{~F} 2) \%$ deviations for the night of 1718 September, are plotted in Fig. 9d. This night is definitely the most complicated case encountered in this study. Here, prolonged high level activity, described by intense variations in the $A E$ index (evident also in both auroral oval activity indices), resulted in a consistent increase in $h m \mathrm{~F} 2$. At the end of this event, the deviation in $h m \mathrm{~F} 2$ reached $60 \%$ with respect to normal values.

The above observations and the corresponding results from the analysis of all nighttime intervals analyzed in this study are summarized in Table 1 . The dates of the aurora associated F2-layer uplifting and the start time of each energy ejection event is noted in the first column of Table 1 , while the next three columns refer to auroral energy injection characteristics: the maximum value of the $A E$ index for each event is given in the second column, the duration of each event in hours is noted in the third column and the estimated amount of the dissipated Joule heating in the auroral oval is shown in the fourth column. The last two columns give information about the related height enhancement events: the maximum (\%) deviation of the $h m \mathrm{~F} 2$ with respect to the normal values is given in the fifth column, while the last column shows the observed time delay in between the energy injection events at auroral latitudes, and the height enhancements observed at middle latitude ionosphere.

In conclusion, we denote that energy deposition at auroral latitudes triggers a F2-layer height enhancement that is observable at middle latitudes at F2-layer altitudes with a time delay. No consistent relation was detected between height enhancement characteristics (magnitude or time delay) and the individual activity of each auroral electrojet separately (westward or eastward), but their combined effect seems to 

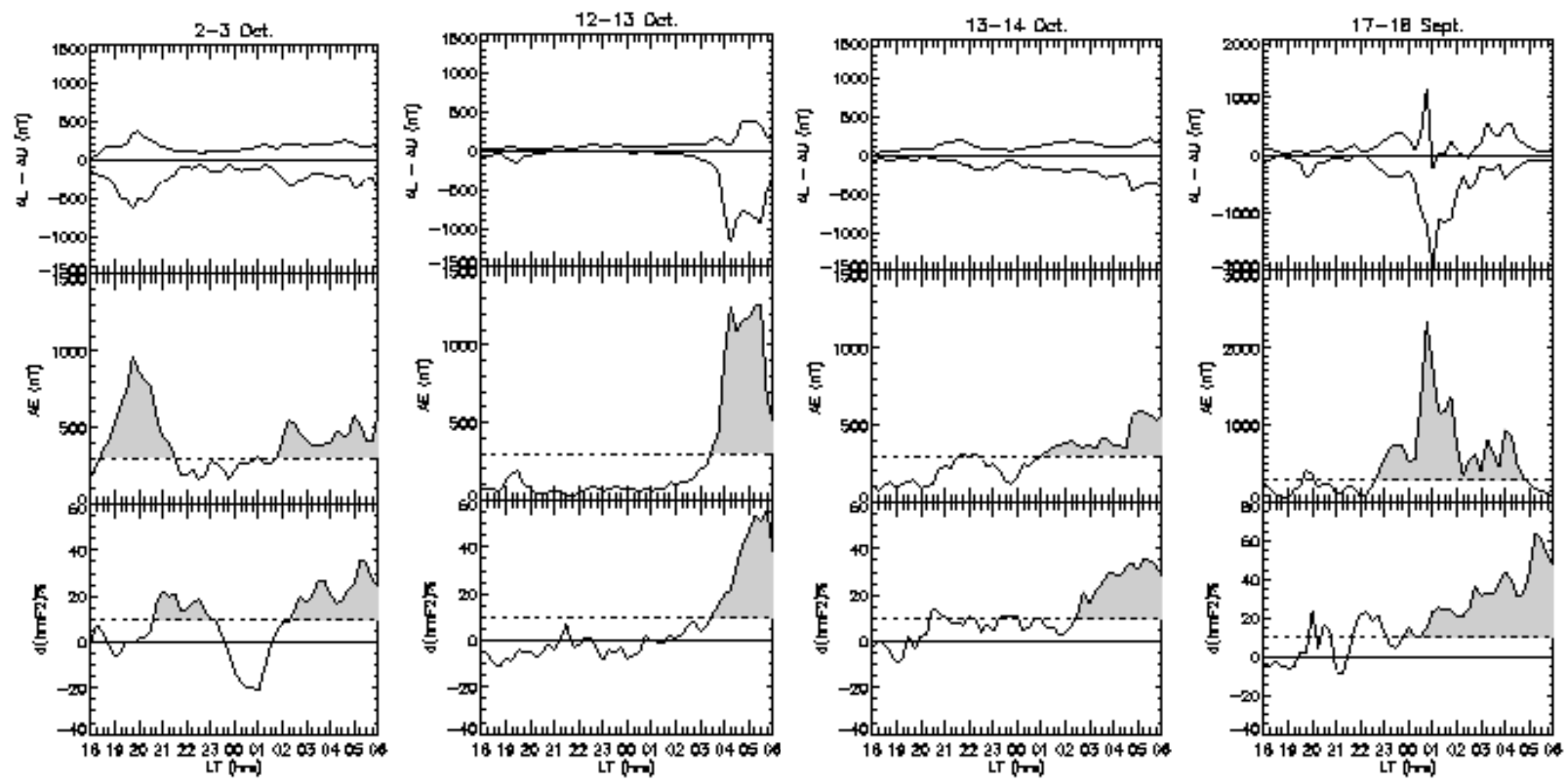

Fig. 9. The development of $A L, A U$ and $A E$ indices is compared with the $\mathrm{d}(h m \mathrm{~F} 2) \%$ deviations individually for four events of nighttime uplifting of the F2-layer. The night hours between 18:00 LT and 06:00 LT are presented in this figure for the nights between 2-3 October (a), 12-13 (b) and 13-14 (c) and 17-18 September (d). The events of height enhancements and the $A E$ peak that caused them are marked with the grey colour.

Table 1. Summary of the auroral oval energy injection events in conjunction with the ionospheric height enhancements at middle latitudes

\begin{tabular}{l|r|c|c|c|r}
\hline Date and start time & Max $A E$ (nt) & $\begin{array}{c}\text { Duration of the } \\
\text { ejection event }(\mathrm{h})\end{array}$ & $\begin{array}{c}\text { Dissipated Joule } \\
\text { energy }\left(10^{21} \mathrm{erg}\right)\end{array}$ & $\begin{array}{c}\text { Max } \\
\mathrm{d}(\mathrm{hm} \text { F2 }) \%\end{array}$ & $\begin{array}{c}\text { Time delay } \\
(\mathrm{min})\end{array}$ \\
\hline 29-30 Sept., 02:45 UT & 590 & 3.0 & 11.1 & 15 & 135 \\
30 Sept.-1 Oct., 19:45 UT & 598 & 1.3 & 4.2 & 19 & 60 \\
30 Sept.-1 Oct., 22:40 UT & 851 & 4.3 & 18.3 & 31 & 105 \\
2-3 Oct., 18:30 UT & 970 & 3.0 & 14.0 & 23 & 120 \\
2-3 Oct., 01:45 UT & 577 & 4.0 & 13.8 & 35 & 35 \\
4-5 Oct., 20:27 UT & 1211 & 2.5 & 12.2 & 30 & 105 \\
4-5 Oct., 23:20 UT & 923 & 4.5 & 26.4 & 32 & 50 \\
5-6 Oct., 18:15 UT & 1319 & 4.0 & 7.2 & 37 & 165 \\
5-6 Oct., 00:10 UT & 534 & 2.0 & 15.7 & 36 & 135 \\
12-13 Oct., 03:25 UT & 1259 & 2.5 & 7.3 & 26 & 5 \\
13-14 Oct., 01:00 UT & 592 & 5.0 & 37.6 & 65 & 90 \\
14-15 Oct., 00:50 UT & 599 & 2.0 & 3.1 & 30 & 55 \\
17-18 Sept., 22:35 UT & 2341 & 6.5 & 12.8 & 30 & 165 \\
18-19 Sept., 00:50 UT & 415 & 1.0 & & \\
19-20 Sept., 23:55 UT & 580 & 4.0 & \multicolumn{2}{c}{} & 170 \\
\hline
\end{tabular}

better describe the ionospheric structure response.

To better organize the above findings and in an effort to quantitatively relate the auroral activity with the ionospheric response at middle latitudes, the rate of $A E$ index increase was estimated for the most clear cases, and is presented in Fig. 10 as a function of the time delay in height enhancement observations with reference to the onset of an energy dissipation episode. It is obvious that the time delay of height enhancements increases with the decreasing $A E$ index derivative, indicating that the height enhancements are strongly associated to the rate of the solar-wind energy dissipation at the auroral ionosphere. Sudden release of the energy at auroral latitudes is followed after a short time delay (probably less than $5 \mathrm{~min}$ ) by an uplifting of the F2-layer (see, for example, the 12-13 October event in Fig. 9b), while gradually driven energy dissipation may affect the ionospheric structure a few hours later (see, for example, the driven event of 13-14 October presented in Fig. 9c). Since the Athens Digisonde observes significant height enhancement only when the $A E$ exceeds $300 \mathrm{nT}$, the dissipated energy may also be a key parameter for height disturbance observations at middle latitudes. In support of this, we present the maximum percentage of 


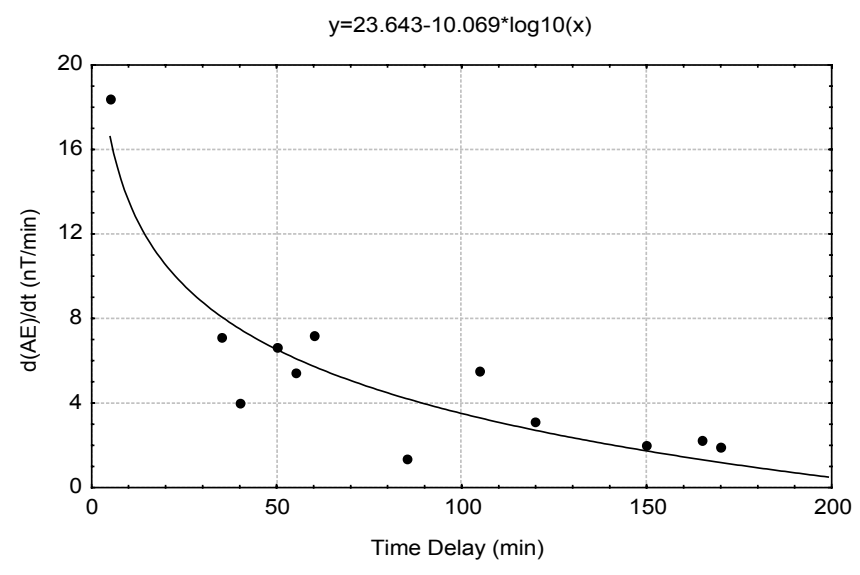

Fig. 10. The rate of $A E$ index increase, estimated for 12 clear cases of nighttime height enhancements, as a function of the time delay in height enhancements observation with reference to the onset of an energy dissipation episode.

$h m \mathrm{~F} 2$ variation versus the dissipated Joule energy in the aurora causing the F2 uplifting event in Fig. 11a, and versus the maximum value of the $A E$ index for each event in Fig. 11b. A clear dependence is evident there, although uncertainties in the estimation of the relevant quantities do not allow us to determine the exact form of the dependence.

Assuming that the height enhancements propagate from auroral latitudes to middle latitudes, such as TID disturbances, and that the time delay is related to the propagation velocity of them, the above statement also holds for the propagation velocities' behaviour and may be an explanation for the large range of velocities that have been reported. More precisely, studies based on meridionally spaced "chains" of ionosondes give high velocity values. For example, Hajkowicz and Hunsucker (1987) found an equatorward propagation velocity of about $800 \mathrm{~m} / \mathrm{s}$ and a constant period of about $135 \mathrm{~min}$. Similar results were reported by Yeh et al. (1994) in a study based on spaced TEC measurement from geostationary satellite signals, and from ionosonde chains. Their derived velocities correspond more to the meridional velocity component of the disturbance front than to the true phase velocity of TID propagation. Taking into account any deviation from the equatorward propagation, these estimated values correspond to much smaller phase velocities. On the other hand, whenever the spaced beam reception method was used at the EISCAT incoherent scatter station, the determined phase velocities never exceeded $400 \mathrm{~m} / \mathrm{s}$ (Ma et al., 1998). Measurements from the MU radar gave even smaller estimates (averaging about $240 \mathrm{~m} / \mathrm{s}$ ) (Oliver et al., 1997), while Super-DARN (Hall et al., 1999) velocities were similar to TID velocities. Furthermore, Afraimovich et al. (2000) devised a technique for determining TID parameters using GPS-arrays whose elements can be selected from a large set of GPS stations and determined a phase velocity of about $300 \mathrm{~m} / \mathrm{s}$.

Supposing that the source region of the observed distur-
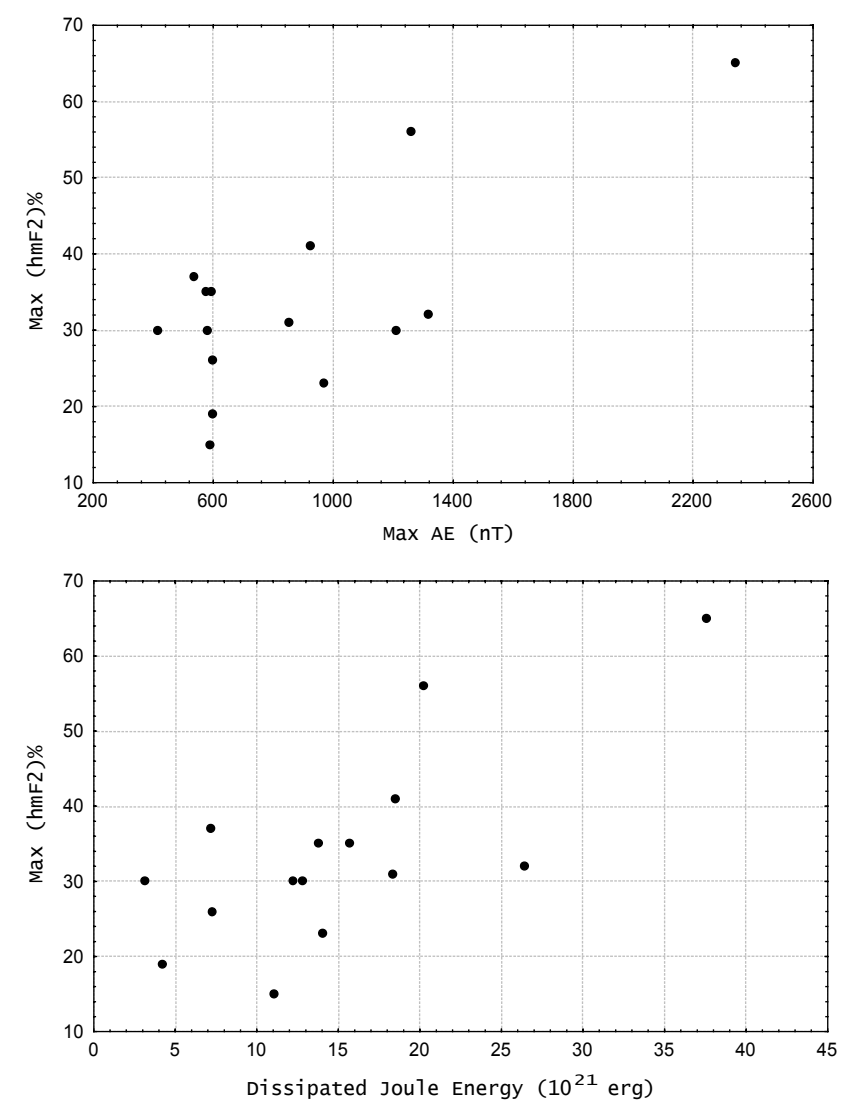

Fig. 11. (a) The maximum $\mathrm{d}(h m \mathrm{~F} 2) \%$ variation versus the dissipated Joule energy in the aurora causing the F2 uplifting event. (b) The maximum $\mathrm{d}(h m \mathrm{~F} 2) \%$ variation versus the maximum value of $A E$ index for each event.

bances is the auroral oval region $\left(\sim 60^{\circ}\right)$ and assuming that they propagate in an equatorward direction, rough estimates of their propagation velocities can be made. In the cases presented above, the propagation velocity ranges from $270 \mathrm{~m} / \mathrm{s}$ to $1280 \mathrm{~m} / \mathrm{s}$, which again correspond better to the meridional velocity component of the disturbance front than to the true phase velocity propagation. But since deviation of the azimuth of TID propagation from the equatorward direction to the westward direction by $10-20^{\circ}$, on average, has been reported (Oliver et al., 1997; Ma et al., 1998; Hall et al., 1999; Afraimovich et al., 2000), the true phase velocities may be much smaller.

\section{Discussion and conclusions}

In an effort to define the ionospheric structure at middle latitudes during events of nighttime ionisation enhancements, three storm periods in September and October 2000 were analyzed, when six distinct magnetic storms were determined. These storms were also analyzed by Belehaki and Tsagouri (2002) in light of the global solar wind-magnetosphereionosphere interaction using solar wind data, magnetospheric indices and ionospheric observations from an EW and NS 
chain of middle latitude stations for each storm event. The data analysis gave evidence that the solar wind conditions leading to storm events, which are reflected in $D_{s t}$ development, are closely related to the occurrence of nighttime positive effects at middle latitudes. In particular, it was found that systematic nighttime positive effects were observed at middle latitudes during gradually driven magnetic storms. An interesting remark was that they were always associated with F2 peak height enhancements. The opposite, however, was not always valid, since peak height enhancements could also be followed by nighttime ionisation depletions.

The height variations for various plasma frequencies during nighttime hours were studied in detail with observations from the Athens Digisonde. The height enhancements were estimated to be as much as $60 \%$ from their corresponding quiet values, having wave-like characteristics, which were found to be quite similar in both ionisation enhancement and depletion periods. Their periodicity ranges from $1 \mathrm{~h}$ to $5.5 \mathrm{~h}$, with a tendency for smaller periodicities to occur during ionisation enhancements and before local midnight, when the ionisation density appears greater. This dependence on ionisation density may be a possible explanation for the wavelike enhancement's observation to be more evident during nighttime positive effects. Moreover, a dependence of the periodicity and of the amplitude on the frequency and/or altitude was indicated that might be explained in terms of the atmospheric density dependence on altitude (Richmond and $\mathrm{Lu}, 2000$ ). A rather consistent feature is their rapid attenuation in daytime. This attenuation is attributed to the ion drag that retards the gravity wave propagation associated with the high ionization density of the F-region in daytime (Hajkowicz, 1990; Balthazor and Moffett, 1999).

Investigating the effect of the auroral oval activity on the ionospheric response over Athens, the relation of the $A E$ increase rate with the time delay in observing height enhancements was determined with reference to the onset of each energy dissipation episode. It is concluded that the time delay of height enhancement increases with decreasing the $A E$ time derivative, indicating that the occurrence of height enhancements is strongly associated with the rate of the solarwind energy dissipation in the auroral ionosphere.

Taking into account the wave-like character of height enhancements and their correlation with the auroral oval activity, these perturbations they may be considered as TID manifestations. Assuming then that they propagate from auroral latitudes to middle latitudes, such as TID disturbances, and that the time delay is related to their propagation velocity, the above statement also holds true for the propagation velocities' behaviour and may be an explanation for the large range of velocities that have been reported. TID consideration could justify a possible explanation for ionisation enhancements (Prölss, 1993; Miller, 1997), although the lack of ionisation in the night-side hemisphere does not support any traditional scenario in ionisation enhancements attribution. Indeed, no consistent relation between the F2 peak density and height variations were found, so it follows that the variations in the two ionospheric parameters are attributed to two distinct mechanisms. Moreover, the height increases are common features of the ionospheric behaviour during events of either ionisation decreases or increases at night. This is in confirmation of the storm scenario proposed by Prölss (1993) in which changes in layer height are predicted for any local time. An additional feature that supports the idea that a new source of ionisation is responsible for the observed nighttime ionisation enhancements is the very good correlation between the ITEC deviations from their quiet values and the $f o F 2$ deviations. Since a net increase of ionisation is observed during nighttime ionisation enhancements, it follows that the responsible mechanism cannot simply be an internal redistribution of ionisation.

The plasmaspheric fluxes' scenario fits very nicely to our findings and agrees with what was previously suggested (e.g. Rishbeth, 1987; Richards, 1994). The possibility of observing its effects is a question of geomagnetic latitude and of solar wind conditions that triggered the magnetic storm (Belehaki and Tsagouri, 2002). The launch of waves from the auroral oval in any activation of auroral electrojets, according to our findings, is an additional mechanism, which occurs independently of the feeding with ionisation from the plasmasphere.

Summarizing, we can conclude that nighttime ionisation enhancements and nighttime F2 uplifting are attributed to two distinct mechanisms. Height enhancements are wavelike disturbances that most probably originate in the auroral oval region and propagate toward the equator-like TID disturbances. Their observation depends on the ionisation density of the ionosphere, which makes their appearance during ionisation depletion periods less evident. On the other hand, nighttime ionisation enhancements observed in terms of $f o \mathrm{~F} 2$ do not share the same wavy appearance, which may mean that they are not connected to TIDs, nor to auroral oval origin. The increased nighttime density can only be speculated to be due to increased downward fluxes from the plasmasphere (Rishbeth, 1987; Richards, 1994). In fact, the plasmaspheric flux term can also modify the value of $h m \mathrm{~F} 2$ and be a contributor to the increased height observation (Szuszczewicz et al., 1998).

Acknowledgements. We are grateful to the WDC-C2 for Geomagnetism, Kyoto for providing the provisional $D_{s t}$-index and preliminary $A E$ indices. This work was supported by the General Secretariat for Research and Technology of the Greek Ministry for Development under the research project "Installation and development of a fully automated Digisonde by the National Observatory of Athens" (http://www.iono.noa.gr).

Topical Editor M. Lester thanks B. Reinisch and another referee for their help in evaluating this paper.

\section{References}

Afraimovich E. L., Kosogorov. E. A., Leonovick, L. A., Palamartcouk, K. S., Perevalova, N. P., and Pirog, O. M.: Determining parameters of large scale travelling ionospheric disturbances of auroral origin using GPS-arrays, J. of Atmospheric and SolarTerrest. Physics, 62, 553-565, 2000. 
Akasofu S.-I.: Energy coupling between the solar wind and the magnetosphere, Space Sci. Rev., 28, 121-190, 1981.

Balthazor R. L. and Moffett, R. J.: Morphology of large scale travelling atmospheric disturbances in the polar thermosphere, J. Geophys. Res., 104, 15-24, 1999.

Bauske R. and Prolss, G. W.: Modelling the ionospheric response to travelling atmospheric disturbances, J. Geophys. Res., 102, 14 555-14 562, 1997.

Belehaki A. and Tsagouri, I.: On the occurrence of storm induced night-time ionisation enhancements at ionospheric middle latitudes, J. Geophys. Res. (in press), 2002.

Burnside, R. G., Templey, C. A., Sulzer, M. P., Fuller-Rowell, T. J., Torr, D. G., and Roble, R. G.: The neutral thermosphere at Arebico during geomagnetic storms, J. Geophys. Res., 96, 12891301, 1991.

Davis, T. N. and Sugiura, M.: Auroral electrojet activity index $A E$ and its universal time variations, J. Geophys. Res., 71, 785-801, 1966.

Fuller-Rowell, T. J., Codrescu, M. V., Moffett R. J., and Quegan, S.: Response of the thermosphere and ionosphere to geomagnetic storms, J. Geophys. Res., 99, 3893-3914, 1994.

Fuller-Rowell T. J., Codrescu, M. V., Rishbeth, H., Moffett R. J., and Quegan, S.: On the seasonal response of the thermosphere and ionosphere to geomagnetic storms, J. Geophys. Res., 101, 2343-2353, 1996.

Hajkowicz, L. A.: A global study of traveling ionospheric disturbances (TIDs) followinga step-like onset of auroral substorms in both hemispheres, Planet. Space Sci., 38, 913-923, 1990.

Hajkowicz, L. A. and Hunsucker, R. D.: A simultaneous observation of large scale periodic TIDs in both hemispheres following the onset of auroral disturbances, Planet. Space Sci., 35, 785$791,1987$.

Hall G. E., MacDougall, J. W., Cecile, J.-F., Moorcroft, D. R., and St.-Maurice, J. P.: Finding gravity wave source positions using the Super Dual Auroral Radar Network, J. Geophys. Res., 104, 67-78, 1999.

Huang, X. and Reinisch, B. W.: Vertical electron density profiles from the Digisonde network, Adv. Space Res., 18, 6, 121-129, 1996.

Huang, X. and Reinisch, B. W.: Vertical total electron content from ionograms in real time, Radio Sci., 36, 335-342, 2001.

Kamide Y., Yokoyama, N., Gonzalez, W., Tsurutani, B. T., Daglis, I. A., Brekke, I., and Masuda, I.: Two-step development of geomagnetic storms, J. Geophys. Res., 103, 6917-6921, 1998.

Ma S. Y., Schlegel K., and Xu, J. S.: Case studies of the propagation characteristics of auroral TIDs with EISCAT CP2 data using maximum entropy cross-spectral analysis, Ann. Geophysice, 42, 161-167, 1998.

Mansilla G. A. and Manzano, J. R.: Some theoretical aspects of ionospheric storms at middle latitudes, Annali di Geofisica, 4, 511-517, 1998.

Mayaud P. N.: Derivation, Meaning and Use of Geomagnetic Indices, AGU Geophysical Monograph, Series, 1980.
Mayr H. G. and Volland, H.: Composition waves in the thermosphere, J. Geophys. Res., 81, 671-676, 1976.

Miller, C. A.: Electrodynamics of midlatitude spread F2. A new theory of gravity wave electric fields, J. Geophys. Res., 102, $11533-$ $11538,1997$.

Oliver W. L. and Hagan, M. E.: Simulation of a gravity wave over the middle and upper atmosphere radar, J. Geophys. Res., 96, 9793-9800, 1991.

Oliver W. L., Otsuka, Y., Sato, M., Takami, T. and Fukao, S.: A climatology of $\mathrm{F}$ region gravity wave propagation over the middle and upper atmosphere radar, J. Geophys. Res., 102, $14449-$ $14512,1997$.

Potter W. E., Kayser D. C., and Mauersberger, K.: Direct measurements of neutral wave characteristics in the thermosphere, J. Geophys. Res., 81, 5002-5012, 1976.

Prölss, G. W.: On explaining the local time variation of ionospheric storm effects, Ann. Geophysicae, 11, 1-9, 1993.

Reinisch, B. W.: Modern Ionosondes, in: Modern Ionospheric Science, (Eds) Kohl, H., Ruster, R., and Schlegel, K., European Geophysical Society, 37191 Katlenburg-Lindau, Germany, 440458, 1996.

Reinisch, B. W. and Huang, X.: Automatic Calculation of Electron Density Profiles from Digital Ionograms, 3, Processing of Bottomside Ionograms, Radio Sci., 18, 477-492, 1983.

Reinisch, B. W. and Huang, X.: Finding better B0 and B1 parameters for the IRI F2-profile function, Adv. Space Res., 22, 6, 741747, 1998.

Richards, P. G., Torr, D. G., Buonsanto, M. J., and Sipler, D. P.: Ionospheric effects of the March 1990 magnetic storm: Comparison of theory and measurement, J. Geophys. Res., 99, 23359 $23365,1994$.

Richmond, A. D. and Lu, G.: Upper-atmospheric effects of magnetic storms: a brief tutorial, J. of Atmospheric and Solar-Terrest. Physics, 62, 1115-1127, 2000.

Rishbeth, H., Fuller-Rowell T. J., and Rodger, A. S.: F-layer storms and thermospheric composition, Phys. Scr., 36, 327-336, 1987.

Rishbeth, H. and Garriott, O. K.: Introduction to Ionospheric Physics, Academic Press New York and London, 1969.

Szuszczewicz, E. P., Lester, M., Wilkinson, P., Blanchard, P., Abdu, M., Hanbaba, R., Igarashi, K., Pulinets, S., and Reddy, B. M.: A comparative study of global ionospheric responses to intense magnetic storm conditions, J. Geophys. Res., 103, $11665-11684,1998$.

Trinks, H. and Mayr, H. G.: Large scale neutral composition gravity waves in the thermosphere observed by ESRO 4, J. Geophys. Res., 81, 4023-4026, 1976.

Tsagouri I., Belehaki, A., Moraitis, G., and Mavromichalaki, H.: Positive and negative ionospheric disturbances at middle latitudes during geomagnetic storms, Geophys. Res. Lett., 27, 35793582, 2000.

Yeh, K. C., Ma, S. Y., Lin, K. H., and Conkright, R. O.: Global ionospheric effects of the October 1989 geomagnetic storm, J. Geophys. Res., 99, 6201-6218, 1994. 